\title{
Prevalence of Cattle Trypanosomosis and Apparent Density of Its Fly Vectors in Bambasi District of Benishangul-Gumuz Regional State, Western Ethiopia
}

\author{
Morka Amante $\mathbb{B D}^{1,2}$ and Hika Tesgera ${ }^{1,2}$ \\ ${ }^{1}$ School of Veterinary Medicine, Wollega University, P.O. Box 395, Nekemte, Ethiopia \\ ${ }^{2}$ Bedelle National Tsetse and Trypanomososis Investigation and Control Center, Bedele, Ethiopia \\ Correspondence should be addressed to Morka Amante; morka_amante@yahoo.com
}

Received 24 June 2020; Revised 29 August 2020; Accepted 6 September 2020; Published 15 September 2020

Academic Editor: Francesca Mancianti

Copyright (c) 2020 Morka Amante and Hika Tesgera. This is an open access article distributed under the Creative Commons Attribution License, which permits unrestricted use, distribution, and reproduction in any medium, provided the original work is properly cited.

\begin{abstract}
Trypanosomosis is the most serious disease of cattle, which causes great socioeconomic losses in the country. Its socioeconomic impact is reflected on direct losses due to mortality, morbidity, and reduction in milk and meat production, abortion and stillbirth, and also costs associated with combat of the disease are direct losses. A cross-sectional study was carried out to assess the prevalence of cattle trypanosomosis, and the apparent density and distribution of its fly vectors in selected study areas. The methods employed during the study were buffy coat technique for parasitological study and deploying trap for the collection of tsetse flies. A total of 1512 flies were trapped, and among them, 1162 were tsetse flies while 350 were biting flies. Higher apparent density for tsetse fly (7.7 F/T/D) followed by Stomoxys (0.9 F/T/D), Tabanus (0.8 F/T/D), and Hematopota (0.6 F/T/D) was recorded. Out of 638 examined cattle, the overall prevalence of trypanosomosis in the study area was 9.1\% (58/638). Out of positive cases, Trypanosoma congolense (7.7\%) was the dominant trypanosome species followed by Trypanosoma vivax (0.9\%), Trypanosoma brucei $(0.2 \%)$, and mixed infection of Trypanosoma brucei and Trypanosoma vivax (0.3\%). There was no a significant difference $(p>0.05)$ in trypanosome infection between age, sex, and trypanosome species. The prevalence of trypanosomosis on the bases of body condition was $2.8 \%$ for poor, $5.5 \%$ for medium, and $0.8 \%$ for good body condition. The overall prevalence of anemia was (36.8\%), and presence of anemia was higher in trypanosome positive animals (62.5\%) than in negative animals (34.3\%) which is statistically significant $(p<0.05, \mathrm{CI}=1.794-5.471)$. The overall mean packed cell volume (PCV) value for examined animals was $25.84 \pm 0.252$ SE. Mean $(\mathrm{PCV})$ of parasitaemic cattle $(9.1 \%)$ was significantly $(p<0.05)$ lower than that of aparasitaemic cattle (90\%). This survey showed that trypanosomosis is still a core problem for livestock production of the study area. Therefore, more attention should be given to the control of both the disease and its vectors.
\end{abstract}

\section{Introduction}

Ethiopia has a huge and diverse livestock population that plays an important role in the economies and livelihoods of farmers and pastoralists. Livestock are a "living bank" or "living account" for rural and urban poor farmers or livestock owners. They serve as a financial reserve for the period of economic distress such as crop failure as well as primary cash income. Among livestock, cattle are the primary resource for people in Ethiopia. Despite the large animal population, productivity in Ethiopia is low and even below the average for most countries in Eastern and Sub-Saharan African countries, due to poor nutrition, reproduction problems, management constraints, and prevailing animal disease [1].

In fact, livestock may be affected by a variety of diseases and a number of other unhealthy circumstances. Among these, trypanosomosis is one of the major animal health constraints to livestock production in Sub-Saharan Africa [2]. Bovine trypanosomosis is one of the major impediments to livestock development and agricultural production in Ethiopia contributing negatively to the overall development 
in general and to food self-reliance efforts of the nation in particular [3].

Trypanosomosis is a protozoan disease of both human and animals caused by different species of the genus Trypanosoma, unicellular parasites found in the blood and other tissues of vertebrates include livestock, wild life, and people. It is the one of the most important livestock diseases in SubSaharan Africa (SSA) and is present in 37 countries in that region. Trypanosomosis is transmitted to man and animals by a blood-sucking insect, the tsetse fly. Trypanosomosis limited the extension of natural herds, particularly in Africa, where exists the presence of the tsetse fly density access to woodland and savanna areas with good grazing potential [4].

Trypanosoma infects cattle, sheep, camels, goats, horses, and many other domestic and wild mammals. The Trypanosoma species pathogenic to cattle and known to exist in Ethiopia are T. congolense, T. vivax, and T. brucei. They are distributed mainly in the tsetse belt (where the tsetse fly vector exists) of the country, West, Southwest, and southern part of Ethiopia. T. vivax is also found in areas outside of the tsetse belt, where it can possibly be transmitted by mechanical vectors as biting flies [3]. The prevalence varies from locality to locality depending on agroclimatic conditions, seasons, and as part of activities which are intended to control the impact of the disease [5].

Hence, trypanosomosis is a very serious disease of cattle, which causes great socioeconomic losses in the country. Its socioeconomic impact is reflected on direct losses due to mortality, morbidity, and reduction in milk and meat production, abortion and stillbirth, and also costs associated with combat of the disease are direct losses. And hence, studying the prevalence and magnitude of the vector is inevitably important to develop appropriate control measures [3].

In Ethiopia, as mentioned, the disease is more prevalent in the southern and western regions where the primary vector exists. However, in Bambasi District, trypanosomosis was found to be one of the factors that hampered livestock rearing in most peasant associations from researcher observation. Thus, a study on the status of the disease investigating the vectors and their relative abundance is crucial for a successful control in the area. The knowledge of the status of the disease prevalence, its health impact on animals affected, its vector distribution, and the associated risks are very important for understanding the epidemiology of the disease and to devise suitable control measures.

Therefore, the objectives of the study were as follows:

(i) To determine the prevalence of cattle trypanosomosis found in selected areas of Bambasi District (Northwest Ethiopia)

(ii) To determine apparent densities, distribution, and species of tsetse flies and other biting flies in the selected areas

\section{Materials and Methods}

2.1. Study Area. The study was conducted from November 2016 to March 2017 in six peasant associations (PAs) of
Bambasi District of Assosa Zone, Benishangul-Gumuz Regional State. Bambasi District has 38 kebeles (PAs), stretches over an area of $2210.16\left(\mathrm{~km}^{2}\right)$ with a human population of 62693.The region is found in the northwest of the country between the latitude of 9 and $11^{\circ} \mathrm{N}$ and longitude of 34 and $35^{\circ} \mathrm{E}$, and its altitude range is $1500-1900$ meter above sea level. Annual rain fall is between $1350-1400 \mathrm{~mm}$ with unimodal type of rain fall that occurs between April and October. The annual temperature ranges between $21^{\circ} \mathrm{C}-35^{\circ} \mathrm{C}$. The livelihood of the society largely depends on mixed livestock and crop production having a livestock population of 36,735 cattle, 10732 goat, 3739 sheep, 4467 equines, 41438 poultry, and 23423 beehives [6].

2.2. Study Animals and Sample Size. The study was conducted on indigenous cattle breed kept under the extensive husbandry management system from six peasant associations (PAs). The sample size required for assessing the prevalence of trypanosomosis in this study was determined using the formula given by [7] for multisample stage sampling, by using 95\% level of confidence interval, $50 \%$ expected prevalence, and 0.05 desired absolute precision. Thus, 384 cattle were needed for the study. However, to increase the precision, 638 were included.

2.3. Study Design. The PAs were selected based on their accessibility to transport and information from the district's administrative body. Multistage sampling was used to sample animals, where herds were selected from each PA by simple random sampling as a primary sampling unit. From selected herds, individual animals to be sampled were selected by simple random sampling technique as secondary sampling unit.

The age of sampled animals was determined based on owners' information, and they were grouped as young $(\leq 2$ years of age), adults ( $>2 \leq 5$ years), and old ( $>5$ years). Body condition of animals was determined by physical appearance and observation of body conformation.

\subsection{Study Methodology}

2.4.1. Entomological Survey. An entomological study was also carried out to assess the apparent density and the species of tsetse and other biting flies in the study area. During the study, 75 traps were deployed in five selected sites which seemed suitable habitat for tsetse flies. The coordinates of each trap position were recorded with a Global Positioning System (GPS). A total of 55 monoconical and 20 bioconical traps were deployed in five PAs of the district at approximate intervals of $200-250 \mathrm{~m}$. All traps were baited with acetone, octenol, and cow urine filled in separate bottles. After 48 hours of deployment, tsetse flies in the cages were counted and identified based on their habitat (the palpalis group found around lakes and river, fusca groups found in dense forest, and the morsitans group found in savannah area) and morphology to the genus and species level. Other biting flies 
were also identified according to their morphological structures, such as size and proboscis at the genus level.

2.4.2. Survey on Trypanosomosis. Blood samples were collected randomly from cattle of the settlement into the capillary tube after piercing the ear vein by using a lancet. One end of the capillary tube was sealed and centrifuged at $12,000 \mathrm{rpm}$ for 5 minutes to separate the blood cells and to concentrate trypanosomes using centrifugal forces to form the buffy coat. Then, the mean PCV was measured using a hematocrit reader. The capillary tubes were broken just $1 \mathrm{~mm}$ below the buffy coat and expressed on microscopic slide, mixed and covered with $22 \times 22 \mathrm{~mm}$ cover slip. Then, the slide was examined under a $40 \mathrm{x}$ objective of a compound light microscope using the dark ground buffy coat technique to detect the presence of the parasite. For positive cases, in Giemsa-stained blood smears, the morphology of the species can be distinguished by their size, shape, location and size of kinatoplast, position of nucleus, and the attachment and length of flagellum.

2.5. Data Analysis. All the collected raw data were entered into a Microsoft Excel spread sheet program and then transferred to SPSS Version 20 for analysis. The density of fly population was calculated by dividing the number of flies caught by the number of flies caught by the number of deployed and number of day's deployment and expressed as Flay/Trap/Day [8]. The association between trypanosome infection and risk factors (age, body condition, sex, and PA) was determined by invariable logistic regression. Two sample Student's $t$-tests were used to compare mean PCV of study animals. A statistical significant difference between variables exists when $p<0.05$ at $95 \%$ confidence interval (CI).

\section{Results}

3.1. Entomological Result. Glossina morsitans and other biting flies such as Stomoxys, Tabanus, and Hematopota were caught. A total of 1512 flies were trapped, and among them, 1162 were tsetse flies while 350 were biting flies, including 135 Stomoxys, 115 Tabanus, and 100 Hematopota. A total of 1162 tsetse flies caught in five PAs were subjected to sexing. $31.6 \%$ (367/1162) were males, and $68.4 \%$ (795/1162) were females. At all sites in each PA, female tsetse flies were trapped more frequently than males (Table 1).

Out of the total, 1162 (76.8\%) were belonging to tsetse of the species Glossina morsitans submorsitans followed by Stomoxys, 135 (8.6\%), Hematopota, 100 (6.4\%), and Tabanus, 115 (7.4\%). Only Glossina morsitans submorsitans was identified in the survey site with the overall apparent density of 7.7 F/T/D. The highest fly density, 254 (16.7 F/T/D), was observed in the Mender-51 peasant association, and the lowest, 113 (3.8 F/T/D), was recorded in the Mender-47 peasant association in Bambasi District (Table 2).
TABle 1: Proportion of the F/T/per male and female Glossina species in the study area.

\begin{tabular}{|c|c|c|c|c|c|}
\hline \multirow[b]{2}{*}{ Study site } & \multirow{2}{*}{$\begin{array}{c}\text { No. of } \\
\text { traps }\end{array}$} & \multicolumn{4}{|c|}{ Glossina m. submorsitans } \\
\hline & & $\begin{array}{c}\text { Male } \\
(\%)\end{array}$ & $\begin{array}{c}\text { Female } \\
(\%)\end{array}$ & Total (\%) & $\begin{array}{c}\mathrm{F} / \mathrm{T} / \\
\mathrm{D}\end{array}$ \\
\hline Mender-47 & 15 & $52(3.5)$ & $61(4.1)$ & $113(7.6)$ & 3.8 \\
\hline Mender-46 & 15 & $66(4.4)$ & $104(6.9)$ & $\begin{array}{c}170 \\
(11.3)\end{array}$ & 5.7 \\
\hline Laga Warqee & 15 & $60(4)$ & $108(7.2)$ & $\begin{array}{c}168 \\
(11.2)\end{array}$ & 5.6 \\
\hline Qashimando & 15 & $68(4.5)$ & $144(9.6)$ & $212(14.1)$ & 6.9 \\
\hline Mender-51 & 15 & $\begin{array}{c}121 \\
(8.10)\end{array}$ & $378(25.2)$ & $\begin{array}{c}499 \\
(33.3)\end{array}$ & 16.7 \\
\hline Total & 75 & $\begin{array}{c}367 \\
(4.9)\end{array}$ & $795(10.6)$ & $\begin{array}{c}1162 \\
(15.5)\end{array}$ & 7.78 \\
\hline
\end{tabular}

F/T/D = Flay per Trap per Day.

3.2. Parasitological Result. Out of 638 examined cattle, 58 (9.1\%) were found to be positive for trypanosome infection using the buffy coat technique. The predominant trypanosomes species were T. congolense $(n=49,7.7 \%)$ followed by T. vivax $(n=6,0.9 \%), T$. brucei $(n=1,0.2 \%)$, and mixed infection of T. vivax and T. brucei $(n=2,0.3 \%)$. Despite the occurrence of the highest prevalence in Mender-51 (4.5\%) and the lowest in Mender-52 PAs (0.5\%), a significant difference $(p>0.05)$ was not observed (Table 3$)$.

Concerning age categories, $0.9 \%, 5.5 \%$, and $2.7 \%$ trypanosome infection rates were recorded in young ( $\leq 2$ years), adult ( $>2$ years; $<5$ years), and old ( $\geq 5$ years) cattle, respectively (Table 4). Although as age increased, the prevalence rate also increased. None of these differences were statistically significant. The prevalence of females was less than males. However, statistically no significant difference ( $p>0.05)$ was observed between two sex groups.

Of the total 638 sampled animals, $2.8 \%, 5.5 \%$, and $0.8 \%$ prevalence of bovine trypanosomosis was recorded in poor, medium, and good body conditions of the animals, respectively. There was no significant difference $(p>0.05)$ on prevalence of trypanosomosis among animals of different body conditions (Table 4 ).

3.3. Hematological Findings. The mean PCV of anemic $(19.60 \pm 0.260 \mathrm{SE})$ and normal $(29.56 \pm 0.228 \mathrm{SE})$ cattle showed significant difference $(p<0.05)$. The proportion of anemic animals infected with parasites was significant $(p<0.05)$ as compared with nonanemic positive animals (Table 5 ). The risk of being anemic increased by $3.13(\mathrm{CI}=1.794-5.471)$ folds when animals were infected with trypanosome $(p<0.05)$.

The overall mean PCV of parasitemic and aparasitemic examined animals was $25.8 \pm 0.252 \mathrm{SE}$. The mean PCV value of parasitemic and aparasitemic animals was 23.22 $\pm 0.989 \mathrm{SE}$ and $29.56 \pm 0.228 \mathrm{SE}$, respectively. There was a significant difference between the mean PCV value of parasitaemic and aparasitaemic cattle as the mean PCV of parasitic animals was significantly lower than that of aparasitemic animals $(p<0.05)$ (Table 6). 
TABLE 2: Fly caught number and their apparent density in different selected areas of the district.

\begin{tabular}{|c|c|c|c|c|c|c|c|c|c|}
\hline \multirow[b]{3}{*}{ Study site } & \multirow{2}{*}{\multicolumn{3}{|c|}{$\begin{array}{c}\text { Tsetse flies caught } \\
\text { Glossina m. submorsitans }\end{array}$}} & \multicolumn{6}{|c|}{ Biting flies } \\
\hline & & & & \multicolumn{2}{|c|}{ Stomoxys } & \multicolumn{2}{|c|}{ Tabanus } & \multicolumn{2}{|c|}{ Hematopota } \\
\hline & No. of traps & Total number & $\mathrm{F} / \mathrm{T} / \mathrm{D}$ & Total number & $\mathrm{F} / \mathrm{T} / \mathrm{D}$ & Total number & $\mathrm{F} / \mathrm{T} / \mathrm{D}$ & Total number & $\mathrm{F} / \mathrm{T} / \mathrm{D}$ \\
\hline Mender-47 & 15 & 113 & 3.8 & 27 & 0.9 & 15 & 0.5 & 30 & 1 \\
\hline Mander-46 & 15 & 170 & 5.7 & 32 & 1.1 & 20 & 0.6 & 26 & 0.8 \\
\hline Laga Warqee & 15 & 168 & 5.6 & 20 & 0.6 & 24 & 0.8 & 22 & 0.7 \\
\hline Qashimando & 15 & 212 & 6.9 & 34 & 1.1 & 21 & 0.7 & 9 & 0.3 \\
\hline Mender-51 & 15 & 499 & 16.7 & 22 & 0.7 & 35 & 1.2 & 13 & 0.4 \\
\hline Total & 75 & 1162 & 7.78 & 135 & 0.9 & 115 & 0.8 & 100 & 0.6 \\
\hline
\end{tabular}

F/T/D = Flay per Trap per Day.

TABLE 3: Prevalence of cattle trypanosomosis and identified Trypanosoma species in the study area.

\begin{tabular}{|c|c|c|c|c|c|c|c|}
\hline \multirow{2}{*}{ Sampling villages } & \multirow{2}{*}{ No. of animals examined } & \multirow{2}{*}{ No. of +ve cattle } & \multicolumn{4}{|c|}{ Trypanosoma encountered } & \multirow{2}{*}{ Prevalence (\%) } \\
\hline & & & T. con & T. vivax & T. brucei & T. vivax and T. brucei & \\
\hline Mender-47 & 120 & 7 & 7 & - & - & - & 1.1 \\
\hline Mender-46 & 108 & 4 & 3 & - & - & 1 & 0.6 \\
\hline Laga Warqee & 109 & 5 & 5 & - & - & - & 0.8 \\
\hline Qashimando & 118 & 10 & 10 & - & - & - & 1.6 \\
\hline Mender-51 & 120 & 29 & 21 & 6 & 1 & 1 & 4.5 \\
\hline Mender-52 & 63 & 3 & 3 & - & - & - & 0.5 \\
\hline Total & 638 & 58 & 49 & 6 & 1 & 2 & 9.1 \\
\hline
\end{tabular}

$\mathrm{T}=$ trypanosome; +ve = positive.

TABLE 4: Univariable logistic regression analysis of risk factors with the buffy coat result.

\begin{tabular}{|c|c|c|c|c|c|c|}
\hline Risk factors & Risk factors & No. of animals examined & No. of positive cattle & Prevalence (\%) & OR $(95 \% \mathrm{CI})$ & $p$ value \\
\hline \multirow{6}{*}{ PAs } & Mender-47 & 120 & 7 & $1.1 \%$ & $0.619(.148-2.593)$ & 0.512 \\
\hline & Mender-46 & 108 & 4 & 0.6 & $1.240(.258-5.967)$ & 0.789 \\
\hline & Laga Warqee & 109 & 5 & 0.8 & $1.206(.272-5.353)$ & 0.806 \\
\hline & Qashimando & 118 & 10 & 1.6 & $0.680(.174-2.662)$ & 0.579 \\
\hline & Mender-51 & 120 & 29 & 4.5 & $0.191(.052-.699)$ & 0.012 \\
\hline & Mender-52 & 63 & 3 & 0.5 & - & - \\
\hline \multirow{4}{*}{ Sex } & Total & 638 & 58 & 9.1 & & \\
\hline & Female & 334 & 25 & 3.9 & $1.516(.836-2.749)$ & 0.171 \\
\hline & Male & 294 & 33 & 5.2 & - & - \\
\hline & Total & 638 & 58 & 9.1 & & \\
\hline \multirow{4}{*}{ Age } & Young $(\leq 2)$ & 108 & 6 & 0.9 & $1.537(.558-4.234)$ & 0.406 \\
\hline & Adult $(>2 \leq 5)$ & 352 & 35 & 5.5 & $0.895(.466-1.720)$ & 0.739 \\
\hline & Old $(>5)$ & 178 & 17 & 2.7 & - & - \\
\hline & Total & 638 & 58 & 9.1 & & \\
\hline \multirow{4}{*}{ BCS } & Poor & 140 & 18 & 2.8 & $1.086(.347-3.395)$ & 0.888 \\
\hline & Medium & 413 & 35 & 5.5 & $1.332(.469-3.785)$ & 0.590 \\
\hline & Good & 85 & 5 & 0.8 & - & - \\
\hline & Total & 638 & 58 & 9.1 & & \\
\hline
\end{tabular}

$\mathrm{BCS}=$ body condition score; $\mathrm{CI}=$ confidence interval .

TABLE 5: Univariable logistic regression analysis of anemic and nonanemic cattle.

\begin{tabular}{lcccccc}
\hline Category & No. of examined animals (\%) & Positive (\%) & Overall prevalence (\%) & Mean \pm SE & OR (95\% CI) & $p$ value \\
\hline Anemic $(<25)$ & $235(36.8 \%)$ & $36(15.3 \%)$ & 5.6 & $19.60 \pm 0.260$ & $3.13(1.794-5.471)$ & $p \leq 0.001$ \\
Normal $(\geq 25)$ & $403(63.2 \%)$ & $22(5.4 \%)$ & 3.4 & $29.56 \pm 0.228$ & - & - \\
Total & 638 & 58 & 9.1 & $25.84 \pm 0.252$ & - \\
\hline
\end{tabular}

TABLE 6: Mean PCV value of parasitemic and aparasitemic animals.

\begin{tabular}{|c|c|c|c|c|}
\hline Infection & No. of examined animals & Mean \pm SE & OR $(95 \% \mathrm{CI})$ & $p$ value \\
\hline Parasitemic & 58 & $23.22 \pm 0.989$ & $3.13(1.794-5.471)$ & $p \leq 0.001$ \\
\hline Aparasitemic & 580 & $29.56 \pm 0.228$ & - & - \\
\hline Total & 638 & $25.84 \pm 0.252$ & & \\
\hline
\end{tabular}




\section{Discussion}

4.1. Entomological Study. The entomological survey revealed that Glossina morsitans submorsitans is the only species responsible for the cyclical and three genera of biting flies Stomoxys, Tabanus, and Hematopota, which are responsible in mechanical transmission of the trypanosomosis in the area. Overall apparent densities recorded in the current study were7.7 F/T/D and 2.3 F/T/D for Glossina morsitans submorsitans and biting flies, respectively. The current findings were in agreement with previous works of [9] at Metekel and Awi zones, Northwest Ethiopia, who reported 6.49 F/T/D tsetse fly, and also with findings of 6 [10] at Bure, Ilubabor Zone, southwestern Ethiopia, who indicated the prevalence of 7.23 and $3.13 \mathrm{~F} / \mathrm{T} / \mathrm{D}$ of tsetse fly and biting fly, respectively.

The result of the current entomological survey is lower than the apparent density of tsetse-flies of $14.97 \mathrm{~F} / \mathrm{T} / \mathrm{D}$ found in selected villages of Arbaminch by [11] and the finding reported by [12] of $19.14 \mathrm{~F} / \mathrm{T} / \mathrm{D}$ apparent density, while they are higher than the values found in the study from Mandura District, Northwest Ethiopia, with 0.06 F/T/D apparent density of tsetse flies [13]. Such wide variations could have resulted from differences in season and density of vegetation cover and types of traps deployed, and type and volume of odour attractants utilized during the studies. The low density of tsetse in the study area may have been due to the expansion of settlements and farmlands in the area. It may also be explained by the migration of the game as a result of climate and habitat changes [14].

The sex ratio of tsetse fly in the current study depicted a higher number of female tsetse species, 795 (68.4\%), than male female tsetse species, 367 (31.6\%), which is in line with various reports from the country $[12,14]$. This finding is also in agreement with [15], as female flies would comprise $70-80 \%$ of the mean population. This could be attributed to the longer life span of female compared to male Glossina [16].

4.2. Parasitological Study. The overall prevalence of cattle trypanosomosis in the study area was found to be $9.1 \%$. The current result agreed with the previous report by $[17,18]$ who found $11.7 \%$ at Jabi Tehran District and $8.57 \%$ in western Oromia by [19]. The value found was lower than the report in Gamo-Gofa, $17.33 \%$, by [20] and in Wozeka grid, southern Ethiopia, $27.5 \%$, by [21]. This lower prevalence may occur due to the difference in agroecology of the study area, prophylactic measure, and differences in veterinary services employed in the area which all contribute to the low prevalence of the disease [22].

The overall prevalence of cattle trypanosomosis recorded in current study area was found to be higher than the previous result of $[11,23,24]$ and [25] who reported the prevalence of $2.10 \%, 4.43 \%, 4.86 \%$, and $4.25 \%$ from Didesa District, Arbaminch area, Amhara Region, Northwest Ethiopia, and Ilubabor Zone, southwestern Ethiopia, receptively. The variation between reports might be due to the difference in the management system, season of the study period, the development of drug resistance, and the increase of tsetse challenge due to higher vector density and lack awareness of the animal owners about the disease in the study area.

Three species of trypanosomes were observed in hematological examination, namely, T. congolense, T. vivax, T. brucei, and mixed infection of T. vivax and T. brucei. This study shows that $T$. congolense was the dominant (84.5\%), followed by $\mathrm{T}$. vivax, mixed infection of $T$. vivax and T. brucei, and T. brucei alone. This result was in agreement with [16] who stated that the predominance of $T$. congolense infection in cattle may be also due to the high number of serodems of T. congolense as compared to T. vivax and the development of better immune response to $T$. vivax by the infected animal. In addition, [26] reported that the dominant trypanosome species in upper Didessa valley of tsetseinfested regions was T. congolense. Moreover, [27] stated that the most prevalent trypanosome species in tsetseinfested areas of Ethiopia are T. congolense and T. vivax.

The prevalence of cattle trypanosomosis was assessed between sexes of animals in the 58 trypanosome positive animals; 25 (3.9\%) of them were female animals, and $33(5.2 \%)$ of them were male. The trypanosome infection in female animals was similar to male animals as no significant difference was observed $(p>0.05)$; this shows that both male and female cattle are equally susceptible to trypanosomosis infection. This result agrees with the results of [28] and also of [29] who also obtained no significant difference in susceptibility between the two sexes. This also shows equal exposure to the vector of the parasite [30].

As regards the occurrence of the disease in three different body conditions (poor, good, and medium) among the total 638 sampled animals, the highest prevalence was observed in the medium body condition (5.5\%) followed by poor (2.8\%) and good $(0.8 \%)$ body conditions, although the difference was not significant $(p>0.05)$. Due to poor body condition, animals are highly susceptible to diseases. This is in line with that emaciated animals are more infected than others, which supports the previous study of [31].

Odds ratio indicated that poor body condition animals are affected eight and five times more than medium and good body condition animals, respectively. This result was in disagreement with [32], who stated that the prevalence of the disease is high in good body condition.

In the current study, highest prevalence of the diseases was $5.5 \%$ in adult followed by $2.7 \%$ in old and $0.9 \%$ in young animals. This could be associated to the fact that animals travel long distance for feed and draught as well as for harvesting crops to tsetse high challenge areas. Young animals are also naturally protected to some extent by maternal antibodies. There was no statistically significant difference between age groups $(p>0.05)$. This result was in agreement with the previous research reported by [33] who stated that there is no statistically significant difference between age groups of the animals.

The mean PCV value of parasitemic animals was found to be $23.22 \pm 0.989 \mathrm{SE}$ which is significantly lower $(p<0.05)$ than the aparasitemic one which was $29.56 \pm 0.252$ SE. This finding is aligned with previous work by $[17,34]$. In the contrary, the number of cattle aparasitemic but anemic was 
also considerable. The overall incidence of anemia was $36.8 \%$ in the research area, and the presence of anemia was higher in trypanosome positive animals (62.5\%) than negative animals (34.3\%) (Table 5). This may be due to the contribution of trypanosomosis for causing anemia in infected animals. This finding agreed with previous reports by [26] in western Ethiopia in upper Didessa valley. The difference in mean PCV value between parasitemic and aparasitemic animals indicates that trypanosomosis is involved in reducing the PCV values in the infected animals [35].

Among the anemic animals, $31.2 \%$ of them were negative to trypanosome infection. This is because the observed anemia can also be caused by other concurrent diseases that can cause anemia such as blood-sucking gastrointestinal parasites, hemiparasite, and malnutrition [36]. However, $3.5 \%$ of the cattle with normal PCV value were also found infected by trypanosome and this result is in line with [36] report from East Wollega Zone. This might happen due to the ability of trypanosome positive animal to maintain their PCV value or delayed recovery of the anemic situation after current treatment with trypanocidal drugs. Furthermore, the occurrence of positive animals with normal PCV value might be thought of as recent infections of the animals [37].

\section{Conclusion and Recommendations}

The result of this study $9.1 \%$ shows that that the disease is still widespread and infection with trypanosomosis negatively affects the body condition and PCV profile of animals. Thus, it may be responsible for economic losses in Bambasi District of Benishangul-Gumuz Zone which was assumed to be imposed more by the presence of high density of vectors and the situation is getting worse as the prevention and control a of trypanosomosis is facing a challenge due to limitation of vector control activities and chemotherapy. Therefore, it is imperative to extend and strengthen the comprehensive integrated control strategy approach (vector control and chemotherapy) in the studied areas.

\section{Data Availability}

The data used to support the findings of this study are included with the article.

\section{Conflicts of Interest}

The authors declare that they have no conflicts of interest.

\section{Authors' Contributions}

HT conceived and designed the study. MA analyzed the data.

\section{Acknowledgments}

The authors would like to extend our gratefulness to Wollega University, School of Veterinary Medicine, for all the supports the authors received during the study.

\section{References}

[1] J. Bekele, K. Asmare, and G. Abebe, "Evaluation of deltametrin applications in control of tsetse and trypanosomosis in southern rift valley of Ethiopia," Ethiopian Veterinary Journal, vol. 129, pp. 1-9, 2010.

[2] FAO, Livestock in balance. Food and Agriculture Organization of the United Nations, Food and Agriculture Organization, Rome, Italy, 2009.

[3] G. Abebe, "Trypanosomosis in Ethiopia," Journal of Biological Science, vol. 4, no. 1, pp. 75-121, 2005.

[4] A. Getachew, "Review article trypanasomasis in Ethiopia," Academic Journal of Animal Diseases, vol. 1, no. 1, pp. 11-15, 2005.

[5] A. Tadesse and B. Tsegaye, "Bovine trypanosomosis and its vectors in two districts of Bench Maji zone, South Western Ethiopia," Tropical Animal Health and Production, vol. 42, no. 8, pp. 1757-1762, 2010.

[6] CSA, Agricultural Sample Survey, Statistical Bulletin, Central Statistical Agency (CSA), Addis Ababa, Ethiopia, 2015.

[7] M. Thrusfield, Veterinary Epidemiology, Blackwell Science, Singapore, Singapore, 3rd edition, 2005.

[8] STEP and Ministry of Science and Technology, Southern Tsetse Eradication Project (STEP). Field Operation Manual of Tsetse and Trypanosomosis Control and Monitoring, pp. 5-63, Ministry of Science and Technology, Addis Ababa, Ethiopia, 2012.

[9] M. Solomon and G. Fitta, "Survey on bovine trypanosomosis and its vector in metekal and Awi zones of northwest Ethiopia," Acta Tropica, vol. 117, pp. 146-151, 2010.

[10] NTTICC, National Tsetse and Trypanomososis Investigation and Control Center Report for the Period July 2001 - 6 July 2002, (NTTICC) National Tsetse and Trypanomososis Investigation and Control Center, Badelle, Ethiopia, 2004.

[11] W. Teka, D. Terefe, and A. Wondimu, "Prevalence study of bovine trypanosomosis and tsetsedensityinselected villages of Arbaminch, Ethiopia," Journal of Veterinary Medicine and Animal Health, vol. 4, no. 3, pp. 36-41, 2012.

[12] T. Ayele, D. Ephrem, K. Elias, B. Tamiru, and D. Gizaw, "Prevalence of bovine trypanosomosis and its vector density in daramallo district, southwestern Ethiopia," Journal of Veterinary Advances, vol. 6, pp. 266-272, 2011.

[13] L. Kumela, D. Damena, M. Kedir, and T. Feyera, "Prevalence of bovine trypanosomosis and apparent density of tsetse and other biting flies in Mandura district, northwest, Ethiopia," Journal of Veterinary Science and Technology, vol. 6, p. 229, 2015.

[14] S. G. A. Leak, Tsetse Biology and Ecology: Their Role in the Epidemiology and Control of Trypanosomiasis, CAB International, Wallingford, NY, USA, 1999.

[15] D. Terzu, Seasonal Dynamics of Tsetse and Trypanosomosis in Selected Sites of Southern Nation, Nationalities and Peoples Regional State, Ethiopia, Msc thesis, Addis Ababa University, Faculty of Veterinary Medicine, Debre Zeit, Bishoftu, Ethiopia, 2004.

[16] S. Msangi, "Distribution, density and infection rates of tsetse in selected sites of southern rift valley of Ethiopia," M.S. thesis, AAU-Addis Ababa University, Addis Ababa, Ethiopia, 1999.

[17] M. Bitew, Y. Amedie, A. Abebe, and T. Tolosa, "Prevalence of bovine trypanosomosis in selected areas of Jabi tehenan district, west gojam of Amhara regional state, northwestern Ethiopia," African. Journal. Agriculture Research, vol. 6, pp. 140-144, 2011. 
[18] B. Fayisa, A. Samson, and B. Mihreteab, "Bovine trypanosomosis in selected villages of humbo district, southern Ethiopia," Global Veterinarian, vol. 7, no. 2, pp. 192-198, 2011.

[19] S. Tasew and R. Duguma, "Cattle anaemia and trypanosomiasis in western Oromia State, Ethiopia," Revue de Médecine Vétérinaire, vol. 12, pp. 581-588, 2012.

[20] K. Girma, T. Z. Meseret, D. Haimanot, and L. Firew, "Prevalence of bovine trypanosomosis, its vector density and distribution in and around Arbaminch, gamogofa zone, Ethiopia," Acta Parasitologica Globalis, vol. 5, no. 3, pp. 169-176, 2014.

[21] Z. Abraham and Z. Tesfaheywet, "Prevalence of bovine trypanosomosis in selected district of arba minch, SNNPR, southern Ethiopia," Global Veterinarian, vol. 8, no. 2, pp. 168-173, 2012.

[22] T. Cherenet, R. A. Sani, N. Speybroeck, J. M. Panandam, S. Nadzr, and P. Van den Bossche, "A comparative longitudinal study of bovine trypanosomiasis in tsetse-free and tsetse-infested zones of the Amhara Region, northwest Ethiopia," Veterinary Parasitology, vol. 140, no. 3-4, pp. 251-258, 2006.

[23] M. Ayana, Z. Tesfaheywet, and F. Getnet, "A cross-sectional study on the prevalence of bovine Trypanosomosis in Amhara region, Northwest Ethiopia," Livestock Research for Rural Development, vol. 24, pp. 1-8, 2012.

[24] G. Fayisa, A. Mandefro, B. Hailu, G. Chala, and G. Alemayehu, "Epidemiological status and vector identification of bovine trypanosomiosis in Didesa district of Oromia regional state, Ethiopia," International Journal of Nutrition and Food Sciences, vol. 4, no. 3, pp. 373-380, 2015.

[25] L. Kumela, D. Delesa, T. Senbeta, K. Mohamed, and M. Mulisa, "Prevalence of bovine trypanosomosis and vector distributions in chewaka settlement area of ilubabor zone, south-western Ethiopia," Advances in Biological Research, vol. 10, no. 2, pp. 71-76, 2016.

[26] N. Tewelde, "Study on the occurrence of drug resistant trypanosomes in cattle in the farming in tsetse control areas (FITCA) project in western Ethiopia," M.S. thesis, Addis Ababa University, Debre Zeit, Bishoftu, Ethiopia, 2001.

[27] K. S. Muturi, "Epidemiology of bovine trypanosomsis in selected sites of the Southern Rift valley of Ethiopia," M.S. thesis, AAU-Addis Ababa University, Addis Ababa, Ethiopia, 2001.

[28] T. Daya and G. Abebe, "Seasonal dynamics of tsetse and trypanosomosis in selected sites of southern nation, nationalities and peoples regional state, Ethiopia," Veterinary Journal, vol. 12, no. 2, pp. 77-92, 2008.

[29] M. Adane, "Survey on the prevalence of bovine trypanosomosis in and around bahir dar." DVM thesis, AAU, FVM, debre zeit, Bishoftu, Ethiopia, 1995.

[30] M. A. Quadeer, D. S. Anbirni, M. Usman, O. B. Akogun, M. A. Gundiri, and A. G. Bobbo, "Prevalence of bovine trypanosomosis in bassa local government area, Plateau State, Nigeria," Nigeria Journal of Parasitology, vol. 29, pp. 136-139, 2008.

[31] A. Bizuayehu, B. Basaznew, F. Tewodros, and C. Mersha, "Bovine trypanosomosis a threat to cattle production in Chena district, Southwest Ethiopia," Open Journal of Animal Sciences, vol. 2, no. 4, pp. 287-291, 2012.

[32] A. Mussa, "Prevalence of bovine trypanosomosis in goro wereda, southwest Ethiopia," DVM thesis, AAU-Addis Ababa University, Addis Ababa, Ethiopia, 2002.
[33] A. Sinshaw, "Prevalence of trypanosomosis of cattle in three woreda of Amhara Region," M.S. thesis, FVM, AAU, Debre Zeit, Bishoftu, Ethiopia, 2004.

[34] G. J. Rowlands, S. G. A. Leak, A. S. Peregrine, S. M. Nagda, W. Mulatu, and G. D. M. d'Ieteren, "The incidence of new and the prevalence and persistence of recurrent trypanosome infections in cattle in southwest Ethiopia exposed to a high challenge with drug-resistant parasites," Acta Tropica, vol. 79, no. 2, pp. 149-163, 2001.

[35] R. Murray, P. K. Murray, and W. I. McIntyre, "The accuracy of seasonal forecasts based on pressure anomaly rules," Weather, vol. 32, no. 9, pp. 325-326, 1977.

[36] P. Vanden Bossche, W. Njagu, and C. W. Shereni, "The distribution and epidemiology of bovine trypanosomosis in zimbabwe and an evaluation of the value of an anti-trypanosomal antibody detection elisa as a tool for monitoring," 2001.

[37] D. Garoma, The Prevalence of Bovine Trypanosomosis in Gari Settlement Area of East Wollega Zone, DVM thesis, Jimma University, Jimma, Ethiopia, 2009. 